\title{
MINERALOGIA, GEOQUÍMICA E ORIGEM DOS GOSSANS DESENVOLVIDOS SOBRE O MINÉRIO SULFETADO DE Ni-CU DO DEPÓSITO DE O’TOOLE, MINAS GERAIS, BRASIL
}

\author{
SÔNIA MARIA BARROS DE OLIVEIRA*, ROSELY APARECIDA LIGUORIIMBERNON**, \\ ALAIN BLOT $* * * *$ \& PHILIPPE MAGAT****
}

\begin{abstract}
MINERALOGY, GEOCHEMISTRYAND ORIGIN OF GOSSANS DERIVED FROM THE O'TOOLE Ni-Cu ORE DEPOSIT, MINAS GERAIS, BRAZIL Tropical weathering of the Ni-Cu sulfide orebody at OToole deposit hás created a profile with a lowermost Transition Zone immediately above the fresh ore and an Oxide Zone (gossan) at the top. In the Transition Zone pentlandite is replaced by violarite, with release of iron and nickel. Pyrrhotite alters into violarite and Ni-bearing pyrite. Chalcopyrite is slightly altered into covellite. In the Oxide Zone, limited at the base by the water table, ali sulfides are oxidized to sulphates and goethite. Much of the nickel and copper are leached from this zone. However, the resulting gossan retains the geochemical signature of the primary ore.

Keywords: Gossan, vilarite, $\mathrm{Ni}-\mathrm{Cu}$, goethite

RESUMO A alteracão intempérica do minério sulfetado de $\mathrm{Ni}-\mathrm{Cu}$ do depósito de O'Toole levou à formação de um perfil de alteração composto por uma Zona de Transição sobre o minério fresco e uma Zona Oxidada (gossan) no topo. Na Zona de Transição a pentlandita é substituída pela violarita, com perda de ferro e níquel. A pirrotita altera em violarita e em pirita niquelífera. A calcopirita é apenas ligeiramente afetada, transformando-se muito localizadamente em covelita. Na Zona Oxidada, limitada em sua base pelo lençol freático, todos os sulfetos são oxidados a sulfates e goethita. Uma parte importante do níquel e cobre são lixiviados dessa zona. Entretanto, o gossan resultante conserva a assinatura geoquímica do minério primário.
\end{abstract}

Palavras-chave: Gossan, violarita, Ni-Cu geothita

INTRODUÇÃO Descoberto em, 1983 pela B.P. Mineração Limitada, o depósito de O'Toole é o primeiro depósito brasileiro conhecido de sulfetos associados a sequências komatíticas. Foi através de prospecção geoquímica e geofísica sistemática (Carvalho \& Batista 1983, Taufen \& Brenner 1987) que foram localizados os corpos sulfetados, atingidos pela primeira vez por sondagem realizada sobre um gossan (Brenner et al. 1990).

O depósito, atualmente em fase de desenvolvimento, está localizado no município de Fortaleza de Minas, no sudoeste do estado de Minas Gerais, a 350km de Belo Horizonte e a 400km de São Paulo. E uma região contida no Planalto Sul de Minas, com relevo dissecado a altitudes médias de $900 \mathrm{~m}$. O cinturão ultramáfico hospedeiro da mineralização destaca-se como cristas alinhadas, sustentadas por metachert, que atingem $1000 \mathrm{~m}$ de altitude. A área pertence à Bacia do rio São João, afluente do rio Grande. O clima é tropical de altitude, com temperatura média anual entre 18 e $20^{\circ} \mathrm{C}$ e precipitação média anual de 1500 a $1750 \mathrm{~mm}$ (Cruz et al. 1986).

$\mathrm{O}$ corpo de minério, composto principalmente por sulfetos de $\mathrm{Ni}$, $\mathrm{Cu}$ e $\mathrm{Co}$, está contido na base de uma sequência vulcano-sedimentar de idade arqueana (Brenner et al. 1990). O intenso intemperismo que afetou a região levou à formação de um manto laterítico de espessura e composição variável, dependendo do tipo litológico subjacente. Nos onde aflora o minério sulfetado, desenvolveram-se perfis de alteração capeados por gossans enriquecidos em Ni e Cu (Taufen \& Marchetto 1989).

As reservas estão estimadas em 6,6 milhões de toneladas de minério fresco, com 2,2\%Ni, 0,4\% $\mathrm{Cu}, 0,05 \% \mathrm{Co}$ e $1,2 \mathrm{ppm}$ PGE e Au (Brenner et al. 1990). Sobreposto ao minério, os níveis de gossan perfazem 455.000 de toneladas, com teores de $0,74 \% \mathrm{Ni}, 0,48 \% \mathrm{Cu}, 0,03 \% \mathrm{Co}$ e 1,67ppm PGE (Taufen \& Marchetto 1989).

Eeste trabalho visa caracterizar as associações mineralógicas nos diferentes níveis do perfil de alteração sobre os sulfetos, para estabelecer as filiações entre minerais primários e secundários e, assim, compreender o processo de geração dos gossans.

A MINERALIZAÇÃo PRIMÁRIA As características geológicas regionais e do depósito foram discutidas por diversos autores, entre os quais Teixeira \& Danni (1979), Marchetto et al. (1984), Teixeira et al. (1987), Carvalho (1990) e Brenner et al (1990). E com base nesse último trabalho que serão apresentadas as considerações que se seguem.

$\mathrm{O}$ depósito de O'Toole está associado ao greenstone belt do Morro do Ferro, situado na borda sul do Cráton do Paramirim, Consiste numa suíte vulcano-sedimentar com fonte magmática komatíitica, metamorfizada na fácies xisto-verde superior a anfíbolito. $\mathrm{O}$ greenstone belt aflora intermitentemente como segmentos de até $80 \mathrm{~km}$ de comprimento e $5 \mathrm{~km}$ de largura alongados segundo NW. Esses segmentos são restos erodidos de um sinclinal, preservados no embasamento gnaisse- migmatítico. Três eventos tectônicos regionais acompanhados por dobramentos são reconhecidos no greenstone belt Morro do Ferro, resultando em estruturas dobradas de direcão geral NW. No segmento Fortaleza de Minas, que contém o depósito, o grau de metamorfismo foi o de anfibolito inferior, a temperaturas estimadas de $550^{\circ} \mathrm{C}$.

Os níveis sulfetados estão contidos na parte NW do segmento Fortaleza de Minas do greenstone belt do Morro do Ferro. Nessa área foi reconhecida a sequência $\mathrm{O}^{\prime}$ Toole, portadora do minério, intercalada entre duas sequências dominadas por lavas komatíiticas basálticas transformadas em serpentinitos (Fig. 1). Na sequência O'Toole identificam-se quatro ciclos deposicionais, sendo cada um dos quais composto por serpentinito, clinopiroxenito e anfibolito, e separados por BIFs. O corpo mineralizado está associado à base do ciclo superior, inferior com a BIF do topo do ciclo precedente, e em contato superior com serpentinito maciço. $\mathrm{O}$ corpo de minério é tabular, com cerca de $4 \mathrm{~m}$ de espessura, e situa-se em posição sub-vertical. Compõe-se de cinco bolsões interconectados, numa distância de $1600 \mathrm{~m}$ segundo o mergulho, e é conhecido até uma profundidade de $500 \mathrm{~m}$.

Os minerais de minério predominantes são a pirrotita, pentlandita e calcopirita, constituindo cerca de $30 \%$ do minério, em proporção de 65:30:5. A cobaltita-gersdorfita, os minerais do grupo da platina PGM - , principalmente esperilita, kotulskita-melonita e irarsita, e o ouro encontram-se associados. São acessórios comuns a esfalerita e a ilmenita. Os principais minerais da ganga são serpentina, tremolitaactinolita, talco, magnetita, clorita e cromita.

Segundo Marchetto (1990), a pentlandita ocorre em agregados de cristais sub-euédricos com clivagem octaédrica e textura granular, estando geralmente associados a cristais de pirrotita. A pirrotita pode conter lamelas de exsolução de pentlandita. As análises químicas pontuais, (Tabela 1), mostrasm que a pentlandita tem composição média $\mathrm{Fe}_{2.05} \mathrm{Ni}_{2,40} \mathrm{~S}_{4}$, com razões $\mathrm{Ni} / \mathrm{Fe}$ entre 1,06 e 1,29 e valores relativamente elevados de $\mathrm{Co}$, próximos de $1,0 \%$. A pirrotita apresenta textura anelada, típica de recristalização metamórfica, e sua composição química (Tabela 1) leva a uma fórmula estrutural média $\mathrm{Fe}$, , 908. Os teores de Ni situam-se entre 0,2 e $1,5 \%$ e os de Co são muito baixos, entre 0,0 e $0,1 \%$. A calcopirita ocorre como cristais anedrais e em agrupamentos policristalinos, podendo conter inclusões de esfalerita (Marchetto 1990). A composição química da calcopirita (Tabela 1) leva a uma fórmula estrutural média $\mathrm{Fe}_{1,02} \mathrm{Cu}_{1,02} \mathrm{Cu}_{1,01} \mathrm{~S}_{2}$.

O depósito é interpretado (Brenner et al. 1990) como tendo sido formado no Arqueano, em ambiente vulcano-sedimentar, por acumulacão de líquidos sulfetados imiscíveis no magma ultramáfico. Os sulfetos teriam sido depositados sobre os sedimentos (BIF) da base da sequência, em áreas em que estes se apresentariam com uma menor espessura devido, supostamente, à erosão térmica.durante o fluxo das lavas komatíiticas. Posteriormente, todo o pacote teria sido severamente deformado e metamorfizado. Apesar disso, ao lado das feições

* Instituto de Geociências/NUPEGEL, Universidade de São Paulo, C.P. 11348, 054226-970 São Paulo, Brasil. E-mail: soniaoli @usp.br

** Instituto de Geociências, Universidade de São Paulo, C.P. 11348,054226-970 São Paulo, Brasil

*** ORSTOM 32, Av. Henri Varagnat - 93143 Bondy Cedex França

***** ORSTOM/NUPEGEL, Universidade de São Paulo, C.P. 11348,054226-970 São Paulo Brasil 
típicas de remobilização encontradas no depósito, subsistem feições primárias preservadas.

\section{O PERFIL DE ALTERAÇÃO: AMOSTRAGEM E PROCEDI-} MENTOS ANALÍTICOS Taufen \& Marchetto (1989) definiram o perfil de alteração como sendo composto por três zonas principais

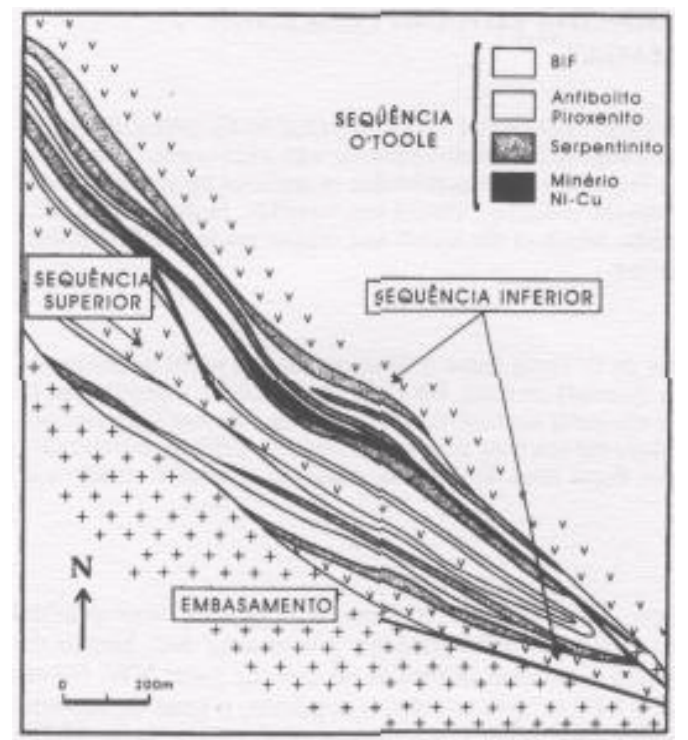

Figura 1 - Mapa geológico da área do depósito de O'Toole (Brenner et al. 1990).
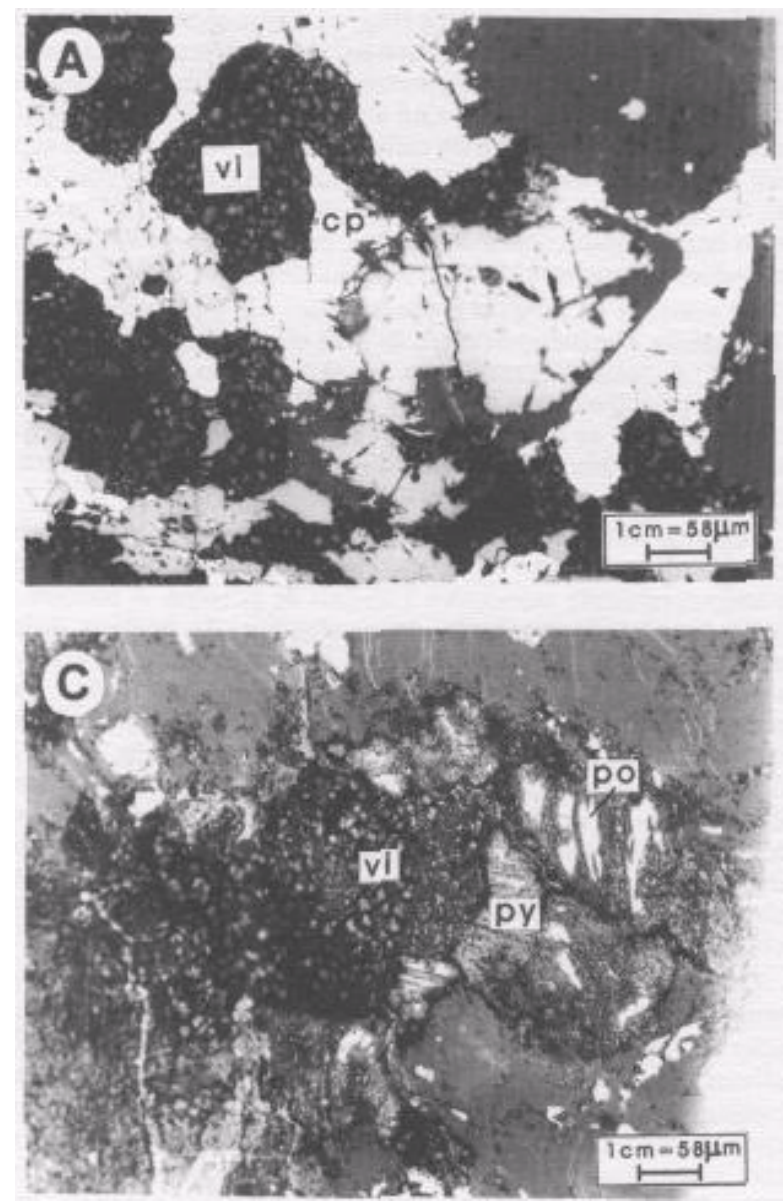

(Fig. 2). O minério fresco grada para uma Zona de Transição caracterizada pela presença de sulfetos secundários (violarita e pirita), a profundidades de cerca de $40 \mathrm{~m}$. Sobrepõe-se a ela uma Zona Oxidada (gossan), de $20 \mathrm{~m}$ de espessura média, dominada por goethita.

Para este trabalho, a amostragem foi realizada na Zona de Transição e na Zona Oxidada. A Zona de Transição está exposta na galeria da mina, onde foram coletadas 7 amostras de minério alterado, contendo proporções variáveis de sulfetos e ganga. A Zona Oxidada está representada por 12 amostras de gossan, recolhidas em duas trincheiras cavadas no manto de alteração sobreposto ao corpo sulfatado, quando dos trabalhos de prospecção. Como não foi possível obter o perfil completo para amostragem, foram necessárias correlações laterais e interpolações para a compreensão das filiações mineralógicas.

As amostras foram moídas, submetidas à difracão de raios $\mathrm{X}$ (Nupegel - USP) e analisadas para $\mathrm{SiO}_{2}, \mathrm{TiO}_{2}, \mathrm{Al}_{2} \mathrm{O}_{3}, \mathrm{Fe}_{2} \mathrm{O}_{3}, \mathrm{MnO}$, $\mathrm{MgO}, \mathrm{CaO}, \mathrm{Na}_{2} \mathrm{O}, \mathrm{K}_{2} \mathrm{O}, \mathrm{P}_{2} \mathrm{O}_{5}, \mathrm{~S}, \mathrm{Ba}, \mathrm{As}, \mathrm{Co}, \mathrm{Hg}$, Ir, Mo, Sb, Se, Cu, $\mathrm{Pb}, \mathrm{Zn}, \mathrm{Ag}, \mathrm{Ni}, \mathrm{Cd}, \mathrm{Bi}, \mathrm{Au}, \mathrm{Pt}, \mathrm{Pd}, \mathrm{V}, \mathrm{ETR}, \mathrm{Y}, \mathrm{Zr}, \mathrm{Sr}, \mathrm{Be}, \mathrm{Br}, \mathrm{Cr}, \mathrm{Cs}$,

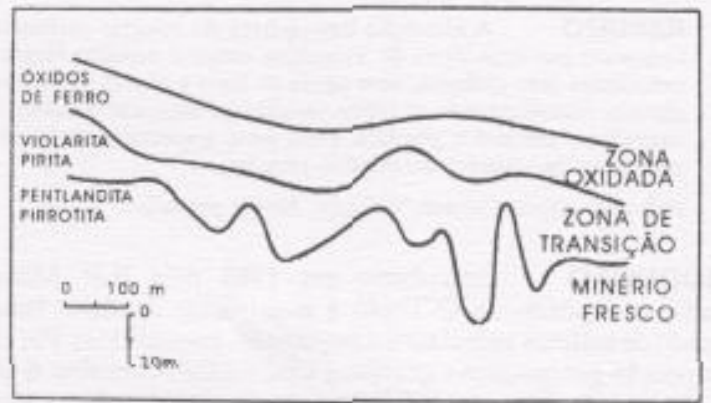

Figura 2 - Seção longitudinal das zonas intemperizadas do corpo de minério de O'Toole (Taufen \& Marchetto, 1989).
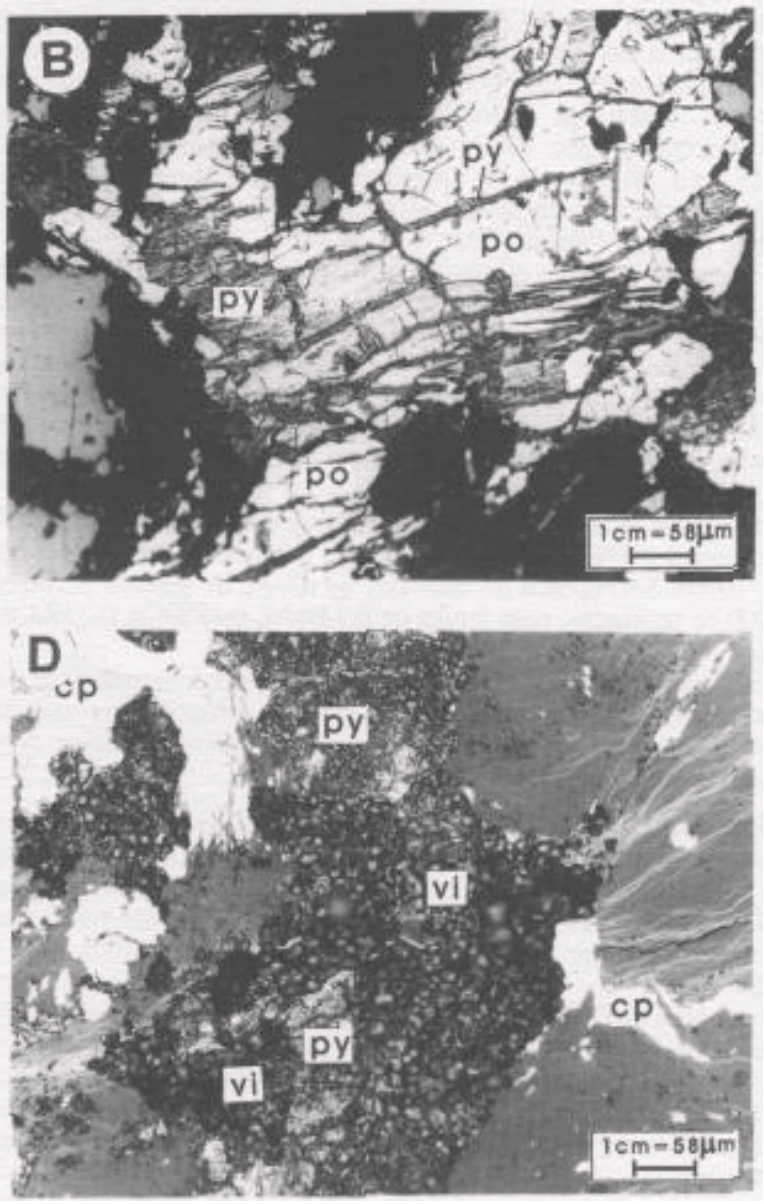

Figura 3 - Fotomicrografias de seções polidas mostrando: (A) - penüandita totalmente transformada em violarita (vi), em contato com calcopirita fresca (cp); (B) - tranformação depirrotita (po) em pirita (py) ao longo dasfraturas; (C) -restos depirrotita (po) dentro da pirita (pi), em contato com violarita (vi), e (D) - substituição por violarita (vi)-pirita (pi) de uma assembleia original de pentlandita-pirrotita, em contato com calcopirita (cp) fresca 
Tabela 1 - Composição química dos sulfetos primários: pentlandita, pirrotita (Marchetto 1990) e calcopirita (este trabalho). Análises por microssonda eletrônica.

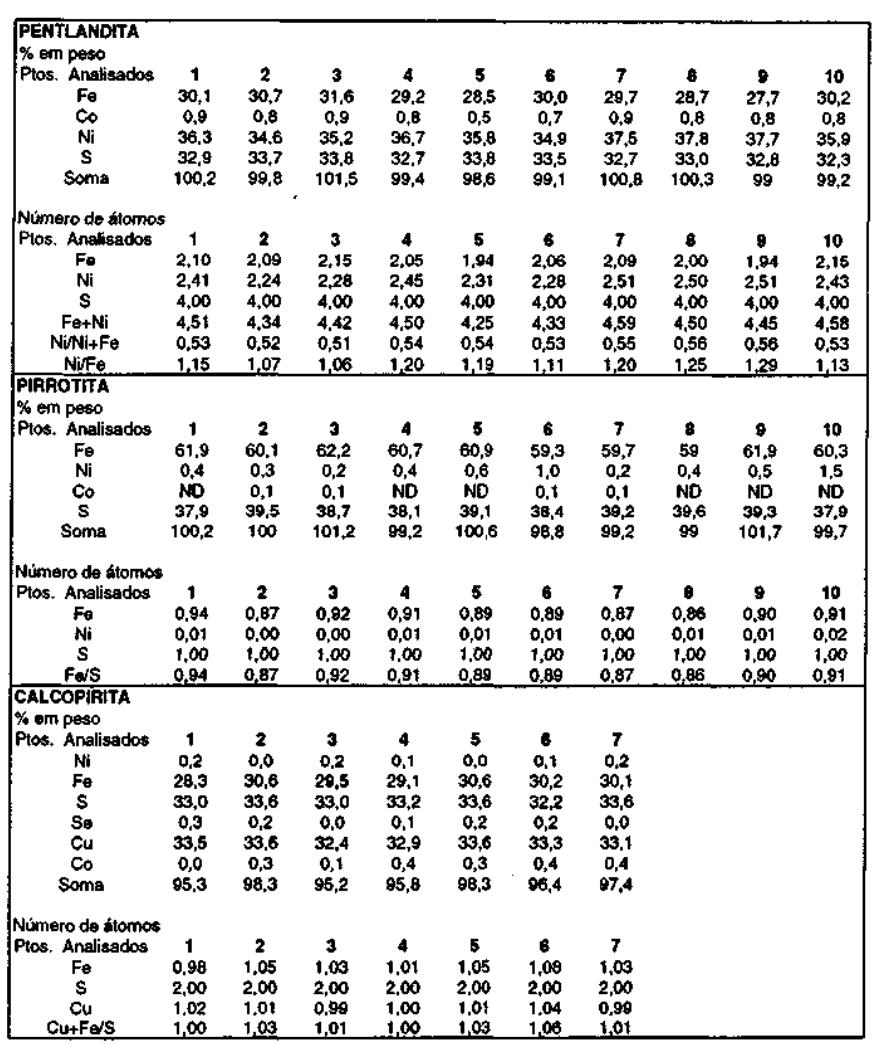

Tabela 2 - Proporções relativas entre os minerais da Zona de Transição. Avaliação por difratometria de raios $X(x x x=$ muito abundante, $x x=$ abundante, $x=$ presente) .

\begin{tabular}{|c|c|c|c|c|c|}
\hline$N^{\circ}$ da amostra & $48:$ & 50 & $74-1$ & $74-3$ & 76 \\
\hline Pirrotita & & $x$ & & $x$ & \\
\hline Calcopirita & $x$ & $x$ & & $x$ & \\
\hline Violarita & $x$ & $x$ & & $x$ & $x$ \\
\hline Pirita & $x$ & & & & $x$ \\
\hline Anfibólio & $\mathbf{x x}$ & $x x$ & $x$ & & \\
\hline Talco & $\mathbf{x}$ & $x$ & $x \boldsymbol{x}$ & & \\
\hline Serpentina & & $x$ & $x \mathbf{x x}$ & $\mathbf{x o x}$ & $x x$ \\
\hline Quartzo & & $x$ & $\mathbf{x x x}$ & $\mathrm{x}$ & \\
\hline Magnetita & $x$ & $x$ & $x$ & $x$ & \\
\hline Goethita & $x$ & $\mathrm{x}$ & $x$ & $x$ & $x x$ \\
\hline
\end{tabular}

Hf, Rb, Sc, Ta, Th, U e W por ICP e ativação neutrônica instrumental no Activation Laboratories Ltd., em Ontario, Canadá. Fragmentos indeformados foram laminados e polidos para exame ao microscópio óptico e metalográfico, ao microscópio eletrônico de varredura com EDS (Laboratório da ORSTOM-Bondy, França) e à microssonda eletrônica (Laboratório do Instituto de Geociências da USP). Os sulfetos secundários, devido à sua porosidade, não permitem polimento adequado, o que resulta em resultados analíticos pontuais nem sempre com bom fechamento.

RESULTADOS Zona de Transição Nesta Zona, a alteração intempérica do minério primário é essencialmente isovolumétrica, e os minerais secundários substitui pseudomorficamente os primários.

Dos três principais sulfetos primários, apenas a pentlandita está ausente, e foi transformada em violarita (Figs 3A, 3C, 3D). A violarita aparece ao microscópio óptico como um material poroso, de textura globular, que em alguns casos mostra um ténue traçado que lembra as clivagens octaédricas da pentlandita.

A pirrotita pode ser encontrada em vários estágios de alteração para pirita. Ocorre desde praticamente fresca, alterada apenas ao longo de suas fraturas (Fig. 3B), até quase toda transformada (Fig. 3C), e mesmo inteiramente transformada (Fig. 3D). Em algumas seções polidas, pode-se observar nas bordas dos cristais de pirrotita o crescimento de violarita que, nesses casos, parece derivar da própria pirrotita.

A calcopirita é o sulfeto primário mais resistente, encontrando-se fresco na Zona de Transição (Figs. 3A, 3D). Apenas localizadamente
Tabela 3 - Composição química global da amostras da Zona de Transição $(*=\%$ em peso, $* *=p p m, * * *=p p b)$.

\begin{tabular}{|c|c|c|c|c|c|c|c|c|c|c|c|}
\hline $\begin{array}{c}N^{5} \text { am. } \\
48 \\
50 \\
74-1 \\
74-3 \\
76 \\
\end{array}$ & $\begin{array}{l}{ }^{*} \mathrm{SiO}_{2} \\
27,24 \\
16,28 \\
32,26 \\
22,82 \\
13,79 \\
\end{array}$ & $\begin{array}{cc}2 & " \mathrm{Al}_{2} \mathrm{O}_{3} \\
4 & 1,61 \\
3 & 0,54 \\
3 & 0,44 \\
2 & 0,88 \\
9 & 1,14 \\
\end{array}$ & $\begin{array}{l}-\mathrm{Fe}_{2} \mathrm{O}_{3} \\
35,52 \\
49,40 \\
49,65 \\
40,26 \\
58,81 \\
\end{array}$ & $\begin{array}{l}\mathrm{MnO}_{2} \\
0,19 \\
0,15 \\
0,04 \\
0,07 \\
0,07 \\
\end{array}$ & $\begin{array}{c}-1 \mathrm{MgO} \\
4,78 \\
5,36 \\
2,30 \\
16,20 \\
7,16\end{array}$ & $\begin{array}{l}{ }^{+} \mathrm{K}_{20} \mathrm{O} \\
0,27 \\
0,10 \\
0,11 \\
0,04 \\
0,09\end{array}$ & $\begin{array}{l}7 \mathrm{Na}_{2} \mathrm{O} \\
0,54 \\
0,38 \\
0,38 \\
0,38 \\
0,39 \\
\end{array}$ & $\begin{array}{l}{ }^{+} \mathrm{Ca} \\
3,6 \\
1,7 \\
0,1 \\
0,1 \\
0,1 \\
\end{array}$ & $\begin{array}{l}90 \\
51 \\
76 \\
19 \\
14 \\
17\end{array}$ & $\begin{array}{c}\mathrm{S} \\
19,41 \\
24,30 \\
1,98 \\
11,13 \\
4,20\end{array}$ & $\begin{array}{l}\text { Soma } \\
93,17 \\
98,27 \\
87,35 \\
91.94 \\
85,82\end{array}$ \\
\hline $\begin{array}{c}N^{0} \text { am. } \\
48 \\
50 \\
74-1 \\
74-3 \\
76 \\
\end{array}$ & $\begin{array}{l}{ }^{n *} \text { As } \\
12 \\
23 \\
53 \\
15 \\
29 \\
\end{array}$ & $\begin{array}{cc}* \mathrm{CO} & { }^{*} \mathrm{C} \\
840 & 170 \\
1200 & 190 \\
230 & 840 \\
620 & 400 \\
330 & 310 \\
\end{array}$ & $\begin{array}{cc}\mathrm{Dr} & * \mathrm{Se} \\
00 & 37 \\
00 & 37 \\
0 & 3 \\
00 & 18 \\
00 & 12 \\
\end{array}$ & $\begin{array}{l}" \mathrm{CH} \\
3107 \\
2897 \\
2834 \\
7899 \\
3257 \\
\end{array}$ & $\begin{array}{c}" \mathrm{Zn} \\
87 \\
96 \\
109 \\
175 \\
205 \\
\end{array}$ & $\begin{array}{l}-\mathrm{Ag} \\
2 \\
1 \\
1 \\
3 \\
1 \\
\end{array}$ & $\begin{array}{c}\mathrm{Ni} \\
28935 \\
\mathbf{5 7 2 0 4} \\
14247 \\
30411 \\
21565 \\
\end{array}$ & $\begin{array}{l}\cdots A u \\
30 \\
47 \\
13 \\
82 \\
110 \\
\end{array}$ & $\begin{array}{c}* *+P 1 \\
744 \\
553 \\
50 \\
198 \\
88 \\
\end{array}$ & $\begin{array}{ll}f+* P d \\
4 \\
487 \\
417 \\
485 \\
943 \\
343 \\
262 \\
\end{array}$ & $\begin{array}{l}220 \\
250 \\
25 \\
99 \\
55 \\
\end{array}$ \\
\hline
\end{tabular}

Tabela 4 - Composição química dos sulfetos secundários da Zona de Transição: violarita (derivada da pentlandita, analisada por microssonda eletrônica), violarita (derivada da pirirotita, analisada por EDS) e pirita (derivada da pirrotita, analisada por microssonda eletrônica).

\begin{tabular}{|c|c|c|c|c|}
\hline \multicolumn{5}{|c|}{ VIOLAATTA (PENTLANDITA) } \\
\hline $\begin{array}{l}\% \text { empeso } \\
\text { Ptos. }\end{array}$ & 1 & 2 & 3 & 4 \\
\hline \multicolumn{5}{|l|}{ Anallisados } \\
\hline $\mathrm{Ni}$ & 29,4 & 33,4 & 35 & 29.7 \\
\hline $\begin{array}{l}F_{0} \\
5\end{array}$ & 25,7 & 21,6 & $\begin{array}{l}20.1 \\
35.7\end{array}$ & 25,1 \\
\hline $\begin{array}{l}5 \\
\text { so }\end{array}$ & $\begin{array}{l}34,6 \\
0,1\end{array}$ & $\begin{array}{c}35,6 \\
0,1\end{array}$ & $\begin{array}{l}35,7 \\
0,2\end{array}$ & $\begin{array}{l}36,6 \\
0,1\end{array}$ \\
\hline As & 0,0 & 0,0 & 0,1 & 0.0 \\
\hline$C_{0}$ & 0,9 & 0,0 & 0,7 & 0,3 \\
\hline $\mathrm{cu}$ & 0.1 & 0,0 & 0.1 & 0,2 \\
\hline Soma & 90,8 & 90,7 & 91,9 & 92,0 \\
\hline \multicolumn{5}{|c|}{ Número deátomos } \\
\hline \multirow{2}{*}{\multicolumn{5}{|c|}{$\begin{array}{c}\text { Ptos. } \\
\text { Analisados }\end{array}$}} \\
\hline & & & & \\
\hline $\mathrm{Ni}$ & 1,87 & 2,05 & 2.14 & 1,78 \\
\hline & 1,71 & 1,39 & 1,29 & 1,58 \\
\hline$s$ & 4,00 & 4,00 & 4,00 & 4,00 \\
\hline $\mathrm{Ni}+\mathrm{Fe}$ & 3,58 & 3,44 & $\mathbf{3 , 4 3}$ & 3,36 \\
\hline $\mathrm{NWNi+Fe}$ & 0.52 & 0,60 & 0,62 & 0,53 \\
\hline $\mathrm{Ni} / \mathrm{Fe}$ & 1,10 & 1,47 & 1.66 & 1,13 \\
\hline
\end{tabular}

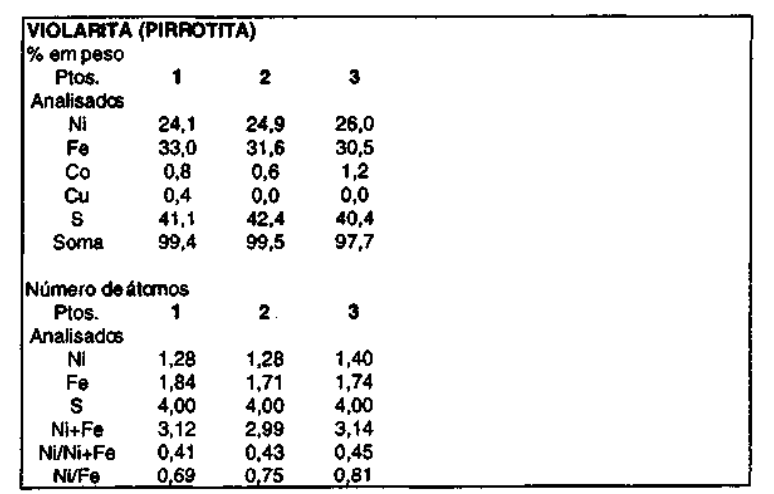

\begin{tabular}{|c|c|c|c|c|c|c|c|}
\hline \multicolumn{8}{|c|}{$\begin{array}{c}\text { PIFITA (PIAFOTITA) } \\
\% \text { em peso }\end{array}$} \\
\hline \multicolumn{8}{|l|}{$\begin{array}{c}\text { Ptos. } \\
\text { Analisados }\end{array}$} \\
\hline $\mathrm{Ni}$ & 0,9 & 1,0 & 1,8 & 2,6 & 3.0 & 3,1 & 4,0 \\
\hline $\mathrm{Fe}$ & 45,4 & 45,2 & 43,8 & 42,5 & 41,8 & 42,4 & 41,3 \\
\hline $\mathrm{s}$ & 47,7 & 49,2 & 45,9 & 45 & 46,8 & 47,0 & 45,6 \\
\hline $\mathrm{Se}$ & 0,3 & 0,1 & 0,0 & 0,1 & 0.0 & 0.1 & 0.1 \\
\hline As & 0,1 & 0,9 & 0,0 & 0,0 & 0.1 & 0,0 & 0.0 \\
\hline Co & 0,4 & 0.5 & 0,6 & 0.1 & 0.5 & 0,2 & 1,0 \\
\hline $\mathrm{Cu}$ & 0,0 & 0.1 & 0,1 & 0,0 & 0,0 & $0, t$ & 0,1 \\
\hline Soma & 94,8 & 96,2 & 92.3 & 90,3 & 92,2 & 92,9 & 92,1 \\
\hline \multicolumn{8}{|c|}{ Número deátcmos } \\
\hline Ptos. & $\mathbf{t}$ & 2 & 3 & 4 & 5 & 6 & 7 \\
\hline $\begin{array}{c}\text { Analisados } \\
F_{\theta}\end{array}$ & & & & & 103 & & 1.04 \\
\hline $\begin{array}{c}F_{\theta} \\
S \\
F \in / S\end{array}$ & 2,00 & 2,00 & 2,00 & 2,00 & 2,00 & 2,00 & 2,00 \\
\hline
\end{tabular}

pode-se perceber nas bordas dos cristais de calcopirita uma incipiente formação de covelita.

Os principais minerais que acompanham os sulfetos são os silicatos inalterados a pouco alterados da rocha encaixante (anfibólios, talco e serpentina), acompanhados por magnetita, quartzo de silicificação supérgena do serpentinito (silcrete) e goethita neoformada. A Tabela 2 mostra uma avaliação das proporções relativas entre as fases das 5 amostras estudadas. 
Tabela 5 - Composição química das goethitas da Zona de Transição. Análises por microssonda eletrônica.
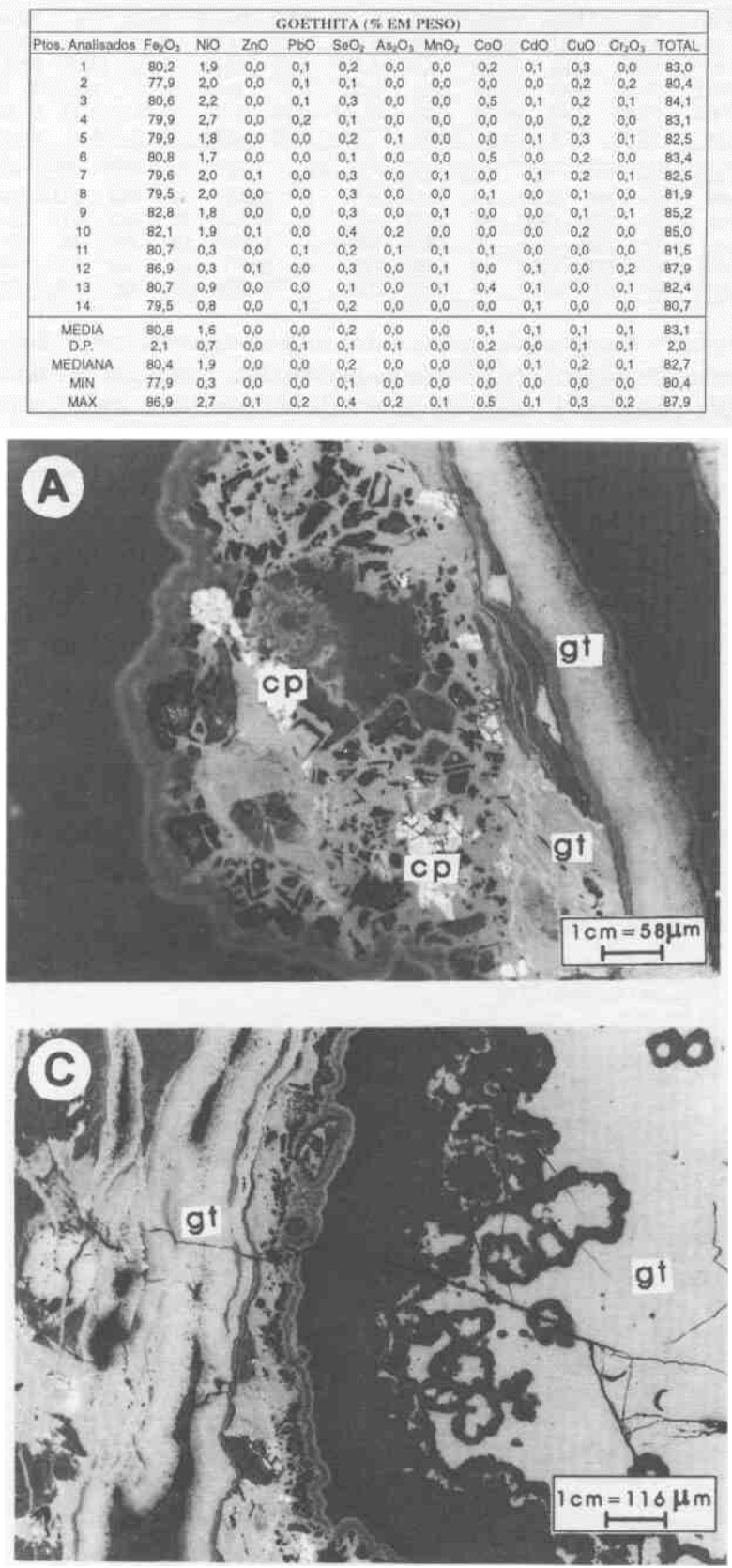

Tabela 6 - Proporções relativas entre os minerais da Zona Oxidada. Avaliação por difratometria de raios $X(x x x=$ muito abundante, $x x=$ abundante, $x=$ presente).

\begin{tabular}{|cccc|}
\hline$N^{\circ}$ da amostra & Goethita & Quartzo & Hematita \\
\hline 53 & $\mathrm{xxx}$ & $\mathrm{xx}$ \\
54 & $\mathrm{xxx}$ & $\mathrm{x}$ \\
55 & $\mathrm{xxx}$ & $\mathrm{xx}$ \\
56 & $\mathrm{xx}$ & $\mathrm{xxx}$ \\
57 & $\mathrm{xxx}$ & $\mathrm{x}$ \\
58 & $\mathrm{xxx}$ & $\mathrm{xx}$ & $\mathrm{x}$ \\
59 & $\mathrm{xxx}$ & $\mathrm{x}$ \\
60 & $\mathrm{xx}$ & $\mathrm{xxx}$ \\
\hline
\end{tabular}
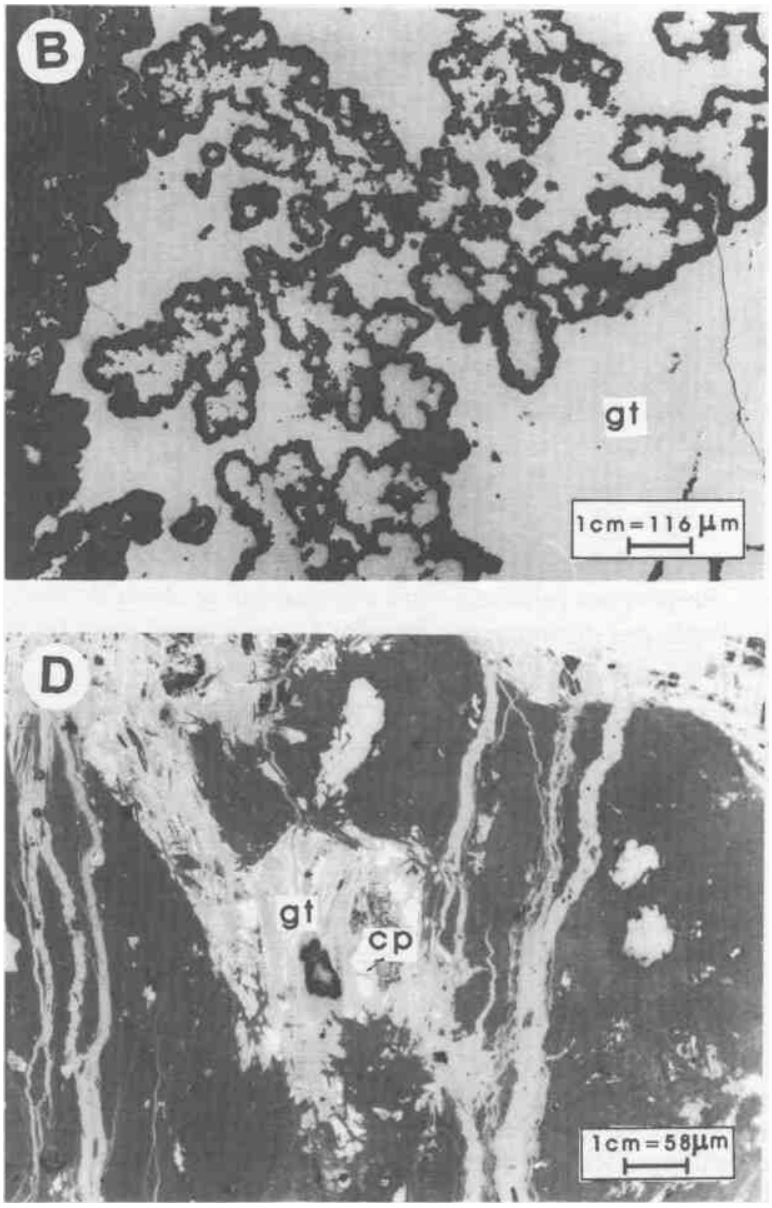

Figura 4 - F otomicro grafias de seções polidas de gossan mostrando: (A) - boxwork cavernoso derivado de sulfetos no plasma goethítico (gt) de um gossan; (B) -textura globular no plasma goethítico (gt) de um gossan; (C) - textura esponjosa e globular no plasma goethítico (gt) de um gossan; e (D) - restos de calcopirita (cp) no plasma goethítico (gt) de um gossan.

A composição química global das amostras dessa Zona (Tabela 3) mostra teores de S entre 2 e $24 \%$ e teores anómalos de As, Co, Cr, Se, $\mathrm{Cu}, \mathrm{Zn}, \mathrm{Ag}, \mathrm{Ni}, \mathrm{Au}, \mathrm{Pt}$, Pd e Ir. Os valores de Co, Ir, Se, Pt e Ni estão estreitamente correlacionados, refletindo a associação dos PGM aos sulfetos de Co e Ni. Essa associação foi descrita por Marchetto 1990 no minério fresco. Sua permanência na Zona de Transição indica que os PGM não foram atingidos pelo intemperismo.

$\mathrm{Na}$ Tabela 4 são apresentados os dados químicos referentes aos sulfetos secundários. A formula estrutural média da violarita derivada da pentlandita é $\mathrm{Fe}_{1,49} \mathrm{Ni}_{1.96} \mathrm{~S}_{4}$, com a razão $\mathrm{Ni} / \mathrm{Fe}$ de 1,09 a 1,66. Os principais traços presentes são o cobalto e o selênio. A soma $\mathrm{Ni}+\mathrm{Fe}$ varia de 3,36 a 3,58, o que excede o valor de 3,0 correspondente à fórmula ideal da violarita $\left(\mathrm{Fe}_{1,0} \mathrm{Ni}_{2,0} \mathrm{~S}_{4}\right.$,). Isso pode ser devido a uma transformação incompleta da pentlandita (fórmula ideal $\mathrm{Fe}_{20} \mathrm{Ni}_{25} \mathrm{~S}_{4}$ ) em violarita, o que resultaria numa mistura dos dois tipos de cristais, pois não parece possível a existência de fases intermediárias (Wattmuff 1974). Outra possibilidade é o erro analítico, comum nesse tipo de material, sobretudo no que diz respeito ao enxofre. O excesso de metal em relação ao $\mathrm{S}$ nas análises de violarita já foi reportada por outros autores que estudaram depósitos semelhantes (Nickel et al. 1974, 1977).

A violarita derivada da pirrotita, de fórmula estrutural média $\mathrm{Fe}_{1,76} \mathrm{Ni}_{1,32} \mathrm{~S}_{4}$, apresenta razões $\mathrm{Ni} / \mathrm{Fe}$ entre 0,69 e 0,81 , sendo, por-tanto, relativamente bem mais pobre em $\mathrm{Ni}$ que a derivada da pentlandita. A soma $\mathrm{Ni}+\mathrm{Fe}$ entre 2,99 e 3,14 está próxima do valor teórico da violarita.

A pirita proveniente da alteração da pirrotita é sempre niquelífera, apresentando também teores significativos de Co e Se. Sua fórmula estrutural média é $\mathrm{Fe}_{1,06} \mathrm{Ni}_{0,06} \mathrm{~S}_{2}$. 

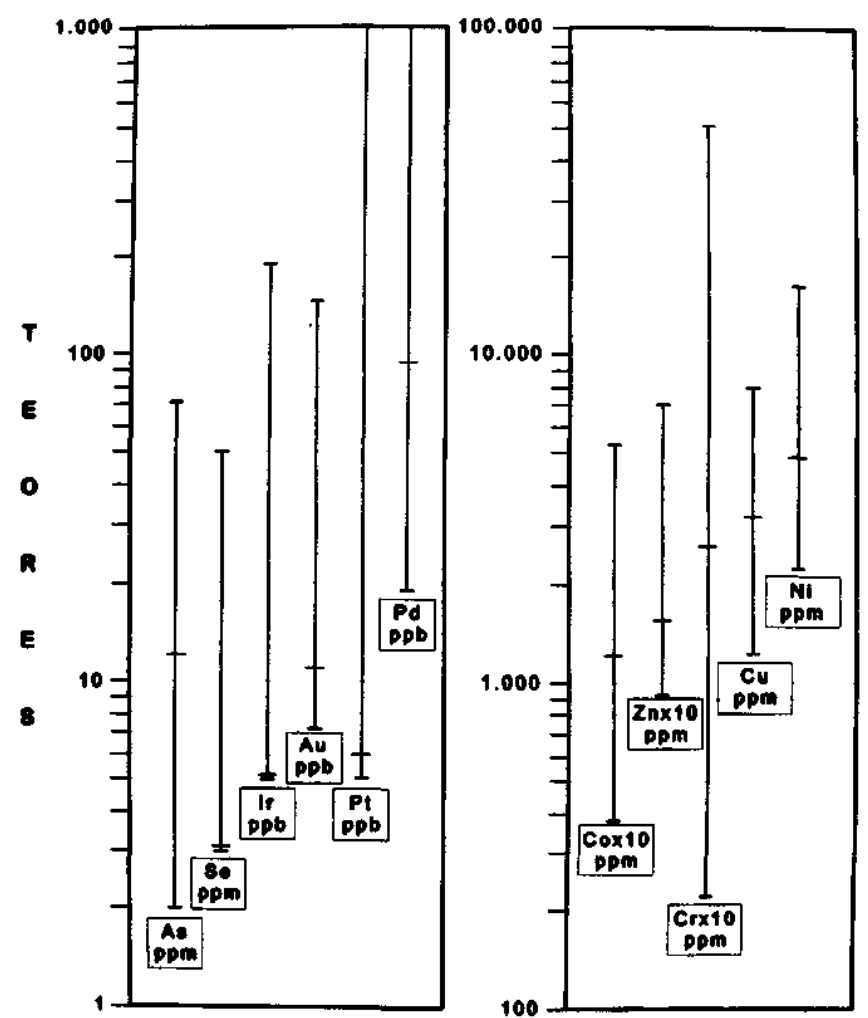

Figura 5 - Intervalos de concentração dos elementos traços (barras vertidas) e medianas (traços horizontais) dos gossans do depósito de O'Toole

Foram também analisadas pontualmente as goethitas da paragênese da Zona de Transição (Tabela 5). Dentre os elementos traços, o níquel é o mais abundante, com média $\mathrm{NiO}=1,6 \%$. Ocorrem ainda, o selênio (média $\mathrm{SeO}_{2}=0,2 \%$ ), o cobre (média $\mathrm{CuO}=0,1 \%$ ) e o cobalto (média $\mathrm{CoO}=0,1 \%$ ). Todos esses elementos apresentam grande heterogeneidade em sua distribuição, como mostram os valores elevados de seus desvio-padrões (Tabela 5). Os teores mais altos de níquel do que cobre revelam que, na Zona de Transição, a goethita provém principalmente dos sulfetos de níquel que já se encontram bem alterados, enquanto que a calcopirita permanece essencialmente fresca.

Zona Oxidada De modo geral, na Zona Oxidada os silicatos primários e os sulfetos primários e secundários já foram totalmente alterados, deixando um resíduo (gossan) de por goethita e quartzo. Em apenas uma amostra foi constatada, por difração de raios X, a presença de pequena quantidade de hematita (Tabela 6).

Nas amostras de gossan analisadas ao microscópio óptico, as texturas reliquiares do minério primário são muito raras, podendo ocorrer localizadamente como cavidades poligonais deixadas pela dissolução dos sulfetos. (Fig. 4A). Porém, na maior parte dos casos, predominam as texturas esponjosa e coloforme, típicas de gossans muito evoluídos (Figs. 4B, 4C). Raramente os gossans contém restos de sulfetos poupados pela alteração e, quando ocorrem, trata-se geralmente de calcopirita (Fig. 4D).

Análises químicas totais de 11 amostras (Tabela 7) mostram a grande heterogeneidade dos gossans, o que deve refletir a natureza heterogénea do minério primário, expressa pelas análises químicas das amostras da Zona de Transição (Tabela 3). Os teores de $\mathrm{SiO}_{2}$ e de $\mathrm{Fe}_{2} \mathrm{O}_{3}$ variam de forma complementar, reflexo de uma composição mineralógica dominada por quartzo e goethita. Os gossans apresentam anomalias geoquímicas significativas de $\mathrm{As}, \mathrm{Co}, \mathrm{Cr}, \mathrm{Se}, \mathrm{Cu}, \mathrm{Zn}, \mathrm{Ag}$, $\mathrm{Ni}, \mathrm{Au}, \mathrm{Pt}$, Pd e Ir. Na Figura 5, os extensos intervalos de variação dos teores desses elementos estão representados em escala logarítmica. Estão também assinaladas as medianas dos teores de cada elemento que, por serem parâmetros menos afetados pêlos valores extremos, são mais significativos que as médias. Os PGE continuam altamente correlacionados entre si (Tabela 8). Isso indica que a intensa alteração intempérica que caracteriza a Zona Oxidada não separou esses elementos, ou porque poupou sua fases portadoras - os PGM -, ou porque, mesmo as tendo destruído, os PGE não foram redistribuídos, graças à sua baixa mobilidade.
Análises pontuais da goethita e de óxidos de Mn do gossan são mostradas na Tabela 9. Na goethita os valores de $\mathrm{NiO}$ são sempre superiores aos de $\mathrm{CuO}$ na média ( $1,1 \%$ e $0,5 \%$, respectivamente) e em cada um dos pontos analisados, analogamente ao que acontece com a goethita da Zona de Transição. No entanto, nos gossans, a diferença entre o conteúdo de $\mathrm{NiO}$ e CuO na goethita é muito menor que na Zona de Transição. Isso se deve a que nos gossans já não há mais calcopirita, cuja alteração liberou o cobre que foi incorporado, pelo menos em parte, pela goethita. Os valores de $\mathrm{SeO}_{2}$ (média=0,2\%) são bastante elevados. Aqui observa-se também uma grande heterogeneidade na distribuição dos elementos traços.

Os óxidos de Mn, presentes em quantidade significativa em apenas uma lâmina de gossan, ocorrem sempre intimamente associados aos óxidos de ferro. A composição química dessas zonas ricas em $\mathrm{MnO}_{2}$ (Tabela 9) mostra que estas constituem eficientes armadilhas de cobre e, em menor grau, de níquel. Foram calculados os coeficientes de correlação entre os elementos analisados nas zonas ricas em óxidos de $\mathrm{Mn}$. As correlações mais significativas são $\mathrm{MnO}_{2} \times \mathrm{K}_{2} \mathrm{O}(\mathrm{r}=0,64)$ e $\mathrm{MnO}_{2}$ x $\mathrm{CuO}(\mathrm{r}=0,85)$, o que indica tratar-se de óxidos de manganês da família do criptomelano, ricos em cobre. A baixa correlação entre $\mathrm{MnO}_{2}$ e $\mathrm{NiO}(\mathrm{r}=0,29)$ indica que o níquel não está associado preferencialmente aos óxidos de $\mathrm{Mn}$.

DISCUSSÃO As mudanças mineralógicas observadas no perfil de alteração são consistentes com um aumento de Eh em direção à superfície. Assim, quando os sulfetos frescos do minério primário entram em contato com as águas do lençol freático na Zona de Transição, ocorre a violaritizacao da pentlandita, liberando $\mathrm{Fe}^{2+}$ e $\mathrm{Ni}^{2+}$. Esse $\mathrm{Ni}^{2+}$ será incorporado pela pirrotita em vias de alteração, produzindo violarita e pirita niquelífera. As reações de violaritizacao da pentlandita (equação 1) e da pirrotita (equação 2), assim como da piritização da pirrotita (equação 3) elevam o número de oxidação do enxofre.

$\mathrm{Fe}_{2,1} \mathrm{Ni}_{2,4} \mathrm{~S}_{4} \rightarrow \mathrm{Fe}_{1,5} \mathrm{Ni}_{2,0} \mathrm{~S}_{4}+0,6 \mathrm{Fe}^{2+}+0,4 \mathrm{Ni}^{2+}+2,0 \mathrm{e}^{-}$

$4 \mathrm{Fe}_{0,9} \mathrm{~S}+1,3 \mathrm{Ni}^{2+} \rightarrow \mathrm{Fe}_{1,8} \mathrm{Ni}_{1,3} \mathrm{~S}_{4}+{ }_{1,8} \mathrm{Fe}^{2+}+3,6 \mathrm{e}^{-}$

$2 \mathrm{Fe}_{0,9} \mathrm{~S}+{ }_{0,1} \mathrm{Ni}^{2+} \rightarrow \mathrm{Fe}_{1,1} \mathrm{Ni}_{0,1} \mathrm{~S}_{2}+0,7 \mathrm{Fe}^{2+}+1,4 \mathrm{e}^{-}$

$\mathrm{Na}$ Zona de Oxidação, acima do lençol freático, os sulfetos secundários e a calcopirita remanescente entram em contato com o oxigénio da atmosfera e se oxidam, transformando-se em sulfatos e goethita. Nessa etapa do processo não só o enxofre é oxidado, mas também o ferro. As equações (4) e (5) descrevem as reações de oxidação da violarita e da pirita, levando ao produto final dominante no gossan: a goethita (6).

$\mathrm{Fe}_{1,5} \mathrm{Ni}_{2,0} \mathrm{~S}_{4}+16 \mathrm{H}_{2} \mathrm{O} \rightarrow 2, \mathrm{ONi}^{2+}+4 \mathrm{SO}_{4}^{2-}+1,5 \mathrm{Fe}^{2+}+32 \mathrm{H}^{+}+31 \mathrm{e}$.

$\mathrm{Fe}_{1,1} \mathrm{Ni}_{0,1} \mathrm{~S}_{2}+8 \mathrm{H}_{2} \mathrm{O} \rightarrow 0,1 \mathrm{Ni}^{2+}+1,1 \mathrm{Fe}^{2+}+2 \mathrm{SO}_{4}{ }^{2-}+16 \mathrm{H}^{+}+10,4 \mathrm{e}^{-}$

$2 \mathrm{Fe}^{2+}+4 \mathrm{H}_{2} \mathrm{O} \rightarrow 2 \mathrm{FeOOH}+6 \mathrm{H}^{+}+2 \mathrm{e}^{-}$

Os elementos de transição são postos em solução, sendo que uma grande parte do níquel e do cobalto e uma quantidade menor de cobre são lixiviados da Zona Oxidada, como mostram os cálculos do balanço de massa efetuados por Taufen \& Marchetto (1989). A mesma coisa deve acontecer com o selênio e o arsênio. Assim, as soluções descendentes, provenientes da Zona Oxidada, constituem uma fonte adicional de elementos de transição incorporados nossulfetos neoformados, provocando um ligeiro enriquecimento supergéno na Zona de Transição, tal como foi sugerido por Taufen \& Marchetto (1989). Os elementos de transição que permanecem na Zona Oxidada são incorporados pela goethita ou, eventualmente, por algum óxido de manganês em vias de formação. A forma de incorporação desses elementos pelo retículo cristalino da goethita parece dar-se predominantemente por substituição isomórfica, conforme sugerido por Oliveira et al. (1996), em estudos por espectroscopia Mõssbauer.

CONCLUSÕES No depósito de O'Toole, o intemperismo químico do minério sulfetado de $\mathrm{Ni}-\mathrm{Cu}$ (pentlandita, pirrotita e calcopirita) desenvolveu um perfil de alteração composto por uma Zona de Transição rica em sulfetos secundários (violarita e pirita), sotoposta a uma Zona de Oxidação rica em óxi-hidróxidos de Fe (goethita).

$\mathrm{Na}$ zona saturada do lençol freático, os sulfetos alteraram-se, sendo o primeiro a pentlandita, dando violarita. Em seguida, alteru-se a 
Tabela 7 - Composição química global das amostras da Zona Oxidada $(*=\%$ em peso, $* *=p p m, * * *=p p b)$

\begin{tabular}{|c|c|c|c|c|c|c|c|c|c|c|c|c|}
\hline$N^{*} \omega_{t}$ & अक\% & $\mathrm{X}_{\mathrm{BO}} \mathrm{O}$ & & $\mathrm{F}_{\mathrm{Q}_{0}}$ & $\mathrm{ThKO}_{2}$ & & & ${ }^{2} \mathrm{KO} \mathrm{O}$ & $\mathrm{NanO}$ & & & Solmm \\
\hline 35 & 1084 & 0.038 & & 6893 & 628 & 0.1 & & 97 & 037 & & & 5153 \\
\hline 52 & 1,02 & 0,59 & & 70,14 & 3,04 & 0,1 & & 0,13 & 0,41 & & & 60.42 \\
\hline 53 & 22,01 & 0,88 & & 42.97 & 2.58 & 0.1 & & 0,10 & 0.35 & & 12 & 5023 \\
\hline 34 & o,es & 0,43 & & 75,61 & 0,30 & 0 & & 0,00 & 0.31 & & & $\$, 56$ \\
\hline 55 & 26,71 & 0,89 & & 0,96 & 0.10 & 0.2 & & 0,01 & 0.34 & & & 8,79 \\
\hline 56 & 51,04 & 0,57 & & 3640 & 0.14 & 0.1 & & 0.07 & 0.42 & 0.1 & & 8069 \\
\hline 37 & 3,35 & 0,34 & & 81.51 & 0.10 & 0.1 & & 000 & 0.33 & 0.1 & & 9901 \\
\hline 59 & 20,67 & 0,58 & & 65.80 & 000 & 0 & & 0.15 & 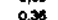 & 0.1 & & ons \\
\hline 59 & 12,24 & 8,00 & & 62.17 & $1 \mathrm{se}$ & 03 & & $\because 10$ & 0.37 & & & \\
\hline & & 0,50 & & 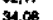 & & & & 01 & 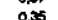 & & & . \\
\hline 74.2 & 23,82 & 0,42 & & 60.54 & 0,02 & 0 & & 000 & 0.38 & 0.1 & & 00 \\
\hline $\mathrm{Nam}$ & $\sqrt{4 x^{4}}$ & 6 & & 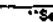 & $\bar{x} \overline{C u}$ & $=2 n$ & & 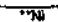 & TWAII & & & क्रमt \\
\hline 61 & 2 & 310 & 6 & 3 & 6427 & 202 & 1 & $\frac{9891}{4681}$ & 18 & 5 & 94 & 5 \\
\hline 52 & 7 & 120 & 42 & 3 & 5657 & 133 & 1 & 4067 & 11 & 6 & 90 & 5 \\
\hline 53 & 4 & 120 & 17 & 3 & 3218 & 152 & 1 & 3063 & 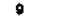 & 8 & 62 & 5 \\
\hline 54 & 2 & 140 & $2 B$ & 3 & 1234 & 600 & 1 & 11253 & 8 & 5 & 19 & 5 \\
\hline 55 & 16 & 100 & 100 & 3 & 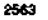 & 211 & 1 & At15 & 27 & 7 & 390 & 5 \\
\hline 56 & 18 & 67 & $\$ 00$ & 7 & 1805 & 115 & 1 & 2406 & 11 & 12 & 322 & 5 \\
\hline 57 & 47 & 58 & $\infty 8$ & $\$ 0$ & $\$ \$ 02$ & 12 & 1 & $97 \notin 4$ & 22 & 40 & 354 & 41 \\
\hline SE & 6.5 & 36 & 2000 & 25 & 4410 & 183 & t & maz & 148 & 1970 & 1194 & 180 \\
\hline 59 & 12 & 80 & 4900 & 3 & 7952 & 345 & 1 & 10453 & 13 & 13 & 201 & $B$ \\
\hline 6 & 2 & 96 & $z$ & 3 & 2717 & 131 & : & 1339 & 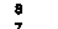 & 6 & 27 & 5 \\
\hline $74-2$ & 71 & 200 & 200 & 3 & 2306 & 83 & 1 & 15943 & & & 19 & 5 \\
\hline
\end{tabular}

pirrotita, seja em violarita, seja em pirita niquelífera, seguida pela calcopirita, cuja alteração é apenas incipiente. Todas essas transformações, típicas da Zona de Transição, ocorreram por pseudomorfose. Com o aprofundamento da frente de alteração, os sulfetos secundários e os restos de sulfetos primários inalterados entraram em

Tabela 8 - Coeficientes de correlação Pearson entre os elementos da

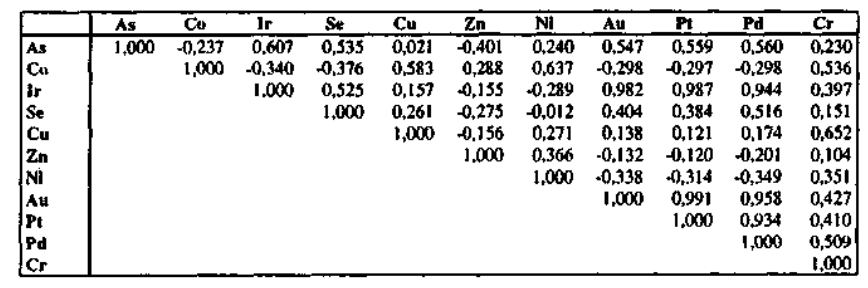

Zona Oxidada (No de amostras $=11, r 95 \%=0,52], r 99 \%=0,685$ )

contato com as águas mais oxidantes da zona insaturada do lençol. Nessas condições, desestabilizaram-se e geraram soluções ricas em sulfato e nos cátions dos elementos de transição. Parte dessas soluções migraram para baixo, alimentando a Zona de Transição, e parte reprecipitou in situ, gerando os gossans que, ao contrário dos materiais de Zona de Transição, são praticamente desprovidos de texturas reliquiares do minério primário. No entanto, guardam a assinatura geoquímica dos sulfetos que lhes deram origem, constituindo materiais importantes na prospecção (Taufen \& Brenner 1987).
Tabela 9 - Composição química das goethitas e dos óxidos de Mn da Zona Oxidada. Análises por microssonda eletrônica.

\begin{tabular}{|c|c|c|c|c|c|c|c|c|c|c|c|c|}
\hline \multicolumn{13}{|c|}{ DETHI } \\
\hline Plos, Analksado & Eos & 140 & $2 n$ & pto & $\mathrm{seO}_{t}$ & $A, 0,0,0$ & $\mathrm{MnO}_{1}$ & $c_{\infty}$ & $\cos$ & $\mathrm{CuO}$ & $\mathrm{CH}_{4} \mathrm{O}_{3}$ & TOTAL \\
\hline$\overline{1}$ & 02,4 & 0.0 & 0.0 & 0,0 & 0,2 & 0,1 & 0,0 & 0,8 & 0,0 & 0,6 & 0.2 & 95,0 \\
\hline 2 & 73,8 & 0,9 & 0,0 & 0,0 & 0,0 & 0,2 & 0,0 & 0.2 & 0.0 & 0.4 & 0.3 & 75.8 \\
\hline 3 & 70,4 & 1,0 & 0,0 & $\mathbb{c}, 0$ & 0,4 & 0.1 & 0,0 & 0,9 & 0,0 & 0,3 & 0,2 & 72,4 \\
\hline 4 & 1,7 & 1.5 & 0,0 & 0.0 & 0.1 & 0,7 & 0,1 & 0.0 & 0,0 & 0,4 & 0,2 & 84,1 \\
\hline 5 & 85,7 & 1,3 & 0,1 & 0,0 & 0,1 & 0.1 & 0.1 & 0.3 & 0,0 & 0.3 & 8.2 & 88.3 \\
\hline 6 & 84,9 & 1,3 & 0,0 & 0.0 & 0,1 & $0+1$ & 0.1 & 0,0 & 0,1 & 0,3 & 0,2 & 87.0 \\
\hline 7 & 85,0 & 1,3 & 0,0 & 0,0 & 0.3 & 0,1 & 0,0 & 0.0 & 0,0 & 0.6 & 0.1 & 87.4 \\
\hline a & 85,0 & 1,2 & 0,1 & 0,0 & 0,1 & 0,0 & 0.1 & 0,0 & 0,1 & 0,8 & 0,9 & 87,4 \\
\hline 8 & 70,2 & 0,5 & 0,0 & 0,0 & 0,0 & 0,1 & 0.1 & 0.8 & 0,1 & 0.6 & 0,1 & $\$ 0.6$ \\
\hline 10 & 85,0 & 0.7 & 0.1 & 0.0 & 0.1 & 0,2 & 0,1 & 0.3 & 0.0 & 0.7 & 0.0 & a7, 3 \\
\hline 11 & 83,3 & 0,7 & 0.0 & 0,1 & 0,3 & 0.1 & 0.1 & 0,0 & 0.0 & 0,5 & 0.1 & 85,1 \\
\hline 18 & $85, \mathbf{4}$ & 1,5 & 0,0 & 0,0 & 0,3 & 0,0 & 0,0 & 0.1 & 0.0 & 0,5 & 0.0 & 97,8 \\
\hline 13 & 78,1 & 1,3 & 0,0 & 0,1 & 0,1 & 0,0 & 0,0 & 0,0 & 0.0 & 0,3 & 0,2 & 80,1 \\
\hline 14 & 84,7 & 1,2 & $0 ; 0$ & 0.1 & 0,3 & 0,1 & 0,1 & 0,0 & 0,0 & 0.4 & 0,1 & $\mathbf{3} 7,0$ \\
\hline 15. & $\mathbf{8 2 . 5}$ & 1,4 & 0,1 & 0,0 & 0,1 & 0,2 & 0,0 & 0,0 & 0,1 & 0,5 & 0,1 & 84,8 \\
\hline 16 & 79,4 & 1,1 & 0,0 & 0.1 & 0,1 & 0,1 & 0.1 & 0.3 & 0.0 & 0,4 & 0.1 & $\mathbf{s 1 , 7}$ \\
\hline$M E$ & 81,6 & 1.7 & 0.0 & 0,0 & 0,2 & 0,1 & 0,0 & 0,2 & 1,0 & 0,5 & 0.1 & 03,9 \\
\hline D.P. & 4,5 & 0,3 & 0,0 & 0,0 & 0.1 & 0.1 & 0.0 & 0.3 & 0.0 & 0.2 & 0.1 & 4,6 \\
\hline MEDIANA & 82.9 & 1.2 & 0.6 & 0,0 & 0,1 & 0,1 & 0,1 & $0_{+} 0$ & 0.0 & 0,4 & 0.1 & B5.1 \\
\hline & 70,4 & 0,5 & 0,0 & 0.0 & 0,0 & $0,0$. & 0,0 & 0,0 & 0,0 & 0,3 & 0 & 32,4 \\
\hline $\mathrm{m} t$ & 85,7 & 1.5 & 0,4 & 0,1 & 0,4 & 0,2 & 0,1 & 0,0 & 0,1 & 0,8 & 0,3 & $B 8,3$ \\
\hline
\end{tabular}

\begin{tabular}{|c|c|c|c|c|c|c|c|c|c|c|}
\hline \multicolumn{11}{|c|}{ ÓXIIOS DE MANGANES (G LM PESO) } \\
\hline P100. Anstisados & $\mathrm{MnC}_{2}$ & $\mathrm{Fen}_{3} \mathrm{O}_{3}$ & $\mathrm{ST}_{2}$ & $\mathrm{Al}_{2} \mathrm{O}_{4}$ & Who & Gad & $k_{2} O$ & NiS & CUS & TOTAL \\
\hline 1 & 15.5 & 39,8 & 7,0 & 0,7 & 0.0 & 0.4 & 0,3 & 0,8 & 0.5 & 65,5 \\
\hline 2 & 45,0 & 24,0 & 1.5 & 0,0 & 0.6 & 0,4 & 0,3 & 2,8 & 2.4 & 76,8 \\
\hline 3 & 60.7 & 6,1 & 0,6 & 0,0 & 1,7 & 0,5 & 0,5 & 2,7 & 3,0 & 75,9 \\
\hline 4 & 74.7 & 0,9 & 0,5 & 0,0 & 0,8 & 0,6 & 1,8 & 1.1 & 2,7 & \$ 1 \\
\hline 5 & 74,6 & 1,6 & 0.5 & 0,0 & 0,0 & 0,3 & 3.9 & $0 ; 0$ & 1,8 & 81,8 \\
\hline 0 & 65,8 & 3,0 & 0,4 & 0,0 & 1,1 & 0,7 & 0,6 & 3.1 & 2,7 & 7.3 \\
\hline 7 & 68.9 & 1.9 & 0,5 & 0.5 & 0.5 & 0,3 & 1,5 & 1,7 & 2.9 & 70.7 \\
\hline $\mathbf{g}$ & $\mathbf{3 2 , 4}$ & 42,5 & 1,9 & 1,0 & 0,3 & 0,2 & 1,3 & 0.0 & 0,8 & 80.4 \\
\hline ? & 16,8 & 44,5 & 7,0 & 0,8 & 0,4 & 0,7 & 0,2 & 0,9 & 0,9 & 72,5 \\
\hline MEDIA & 50.5 & 18.9 & 2,3 & 0.3 & 0.6 & 0.5 & 1,1 & 1,4 & 2,0 & 76.9 \\
\hline D.P. & 23,9 & 28,4 & 3,9 & 0.4 & 0,5 & 0.2 & 9,0 & 1,2 & 1,0 & 5,4 \\
\hline MEDIANA & 40.7 & 6.4 & 0,6 & 0.0 & 0.5 & 0,4 & 0,6 & 1,4 & 2,4 & 77,3 \\
\hline MIN & 15,5 & 0.8 & 0.4 & 0.0 & 0.0 & 0,2 & 0.2 & 0,0 & 0,5 & 65.5 \\
\hline $\max$ & 74,7 & 44.6 & 7.6 & 1,0 & 1,7 & 0.7 & 3.1 & 3,1 & 3.0 & 83.1 \\
\hline
\end{tabular}

A evolução supérgena do minério sulfetado de O'Toole é semelhante, em seus grandes tracos, à descrita nos depósitos de Ni sulfetado de Mt Windarra (Watmuff 1974), Kambalda (Nickel et al. 1974) e Agnew (Nickel et al. 1977), na Austrália. Nesses depósitos, o minério primário é composicionalmente semelhante ao de O'Toole, assim como a paragênese sulfetada secundária. Porém, no limite entre a Zona de Transição e a Zona Oxidada dos depósitos australianos, encontramse carbonatos e sulfatos de $\mathrm{Fe}$ e Ni, que parecem ausentes em O'Toole. Isso pode ser devido a deficiências na amostragem, ou às condições climáticas mais úmidas do sul de Minas em relacão à Austrália, sob as quais esses compostos, se formados, teriam sido dissolvidos.

Agradecimentos Ao Prof. Dr. Sebastião Gomes de Carvalho, que nos acompanhou várias vezes ao campo, e à Empresa de Mineração RTZ que permitiu as visitas à área e facilitou a amostragem. $O$ apoio financeiro para este trabalho foi obtido através do convénio CNPq-ORSTOM(Proc 910196/91-5).

\section{Referências}

Brenner T.L.; Teixeira N.A.; Oliveira J.A.L.; Franke N.D.; Thompson J.F.H. 1990. The O'Toole nickel deposit, Morro do Ferro grenstone belt, Brazil. Economic Geology, 85:904-920.

Carvalho, S.G.; Batista, J J. 1983. Prospecão geoquímica de solo no cinturão vulcano-sedimentar Morro do Ferro, Fortaleza de Minas, Minas Gerais. In: SBC, Simp. Geol. Minas Gerais, 2, Belo Horizonte, Anais 3:248-258.

Carvalho, S.G. 1990. Geologia, petrologia e metalogenia da sequência vulcano-sedimentar de Altinópolis $-M G$. Intitulo de Geociências da Universidade de São Paulo, São Paulo, Tese de doutoramento, 212p.

Cruz, F.F.da; Brenner, T.L.; Moreira, A.F. de S.; Cunha, C.A.B.R. da; Gálio, C.B.M.; Franke, N.D.; Pimentel, R.C. 1986. Jazida de Ni-Cu-Co de Fortaleza de Minas, Minas Gerais. In: C.Schobbenhaus, C.E.S.Coelho (Eds.) Depósitos Minerais do Brasil, vol. II, DNPM, Brasília, 275-306.

Marchetto, C.L.M.; Brenner, T.L.; Franke, N.D.; Cheney, S.T.; Teixeira, N.A.; Moreira, A.E.; Pimentel, R.C.; Gálio, C.B.M. 1984. Geologia e petrologia do segmento do greenstone belt Morro do Ferro a sul de Fortaleza de Minas. In: SBG, Congr. Brás. Geol., 33, Rio de Janeiro, Resumos,149.

Marchetto C.M.L. 1990. Platinum-group minerais in the O'Toole (Ni-Cu-Co) deposit, Brazil. Economic Geology, 85:921-927.

Nickel E.H.; Ross J.R.; Thornber M.R. 1974. The supergene alteration of pyrrhotite-pentlandite ore at Kambalda, Western Austrália. Economic Geology, 69:93-107.

Nickel E.H.; Allchurch P.D.; Mason M.G.; Wilmhurst J.R. 1977. Supergene alteration at the Perseverance Nickel Deposit, Agnew, Western Austrália. Economic Geology, 72:184-203.
Oliveira, S.M.B. de; Imbernon, R.A.I.; Partiti, C.S. de M.; Rechenberg, H.R. 1996. Geoderma,

73:245-256.

Taufen, P.M.; Brenner, T.L. 1987. Geochemical orientation survey of the Fortaleza de Minas O'Toole Ni deposit, southwestern Minas Gerais, Brazil. Geochimica Brasiliensis, 1(1):1-18. distributions at the O'Toole Ni-Cu sulphide deposit, Minas Gerais, Brazil. J.Geochemical. Exploration, 32:185-197.

Teixeira, N,A.; Danni, J.C.M. 1979. Geologia da raiz de um Greenstone belt na região de Fortaleza de Minas, Minas Gerais. Rev. Brás. Geociências, 9:17-26.

Teixeira, N.A.; Gaspar, J.C.; Brenner, T.L.; Cheney, J.T.; Marchetto, C.M.L. 1987. Geologia e implicações geotectônicas do greenstone belt do Morro do Ferro (Fortaleza de Minas - MG). Rev. Brás. Geociências, 17:209-220.

Wattmuff I.G. 1974. Supergene alteration of the Mt Windarra nickel sulphide ore deposit, Western Austrália Mineralium Deposita, 9:199-221.

Manuscrito A-951

Recebido em 23 de dezembro de 1997 Revisão dos autores em 30 de março de 1998 Revisão aceita em 05 de abril de 1998 Mõssbauer spectroscopic study of iron oxides and oxyhydroxides in gossans.

Taufen P.M.; Marchetto C.M.L. 1989. Tropical weathering control of Ni, Cu, Co, and PGE 